\title{
Effect of Salinity on Friction Properties of PTFE/Kevlar Fabric Composites
}

\author{
Gu Dapeng \\ College of Mechanical Engineering \\ Yanshan University \\ Qinhuangdao, Hebei, China \\ e-mail: jsgudapeng@163.com \\ Ma Yanhui \\ College of Mechanical Engineering \\ Yanshan University \\ Qinhuangdao, Hebei, China \\ e-mail: 1063120118@qq.com
}

\author{
Dong Qin \\ College of Mechanical Engineering \\ Yanshan University \\ Qinhuangdao, Hebei, China
}

\author{
Yang Yulin \\ Aviation Key Laboratory of Science and Technology on \\ Generic Technology of Self-lubricating Spherical Plain \\ Bearing \\ Yanshan University \\ Qinhuangdao, Hebei, China
}

\begin{abstract}
Self-lubricating spherical plain bearings are widely used in some important mechanical moving parts. When used in the marine environment, bearing components may be sometimes immersed by seawater. The salinity changes with evaporation or addition of water. This paper discusses the effects of salinity on the friction properties of PTFE/Kevlar fabric composites. Four different salinities seawater were formulated. The friction test was carried out on MMU-5G friction and wear testing machine under seawater. The worn surface morphology was observed by Confocal Laser Scanning Microscopy (CLSM). The result shows that the salinity of seawater has an obvious influence on the friction and wear performance of PTFE/Kevlar fabric composites. The steady-state friction coefficient decreases with the salinity increasing under load 20 MPa, velocity 0.2 $\mathrm{m} / \mathrm{s}$. The wear rates increase with the slide velocity increasing. The suitable salinities range for PTFE/Kevlar fabric composites used in seawater is $3 \% \sim 5 \%$. The mechanoelectrochemical interactions and abrasive wear play an important role in the wear of PTFE/Kevlar fabric composites.
\end{abstract}

\section{Keywords- Salinity;Seawater; Fabric; Friction; Wear}

\section{INTRODUCTION}

In recent years, helicopters, fixed-wing aircraft and other aircrafts regular appear in the marine environment. Self-lubricating spherical plain bearings are widely used in some important mechanical moving parts. The friction and wear performance of self-lubricating spherical plain bearings is the key issue restricting the mobility and safety of aircraft[1-3]. Especially in the marine environment, bearing components may be sometimes immersed by seawater. If bearing components be immersed by seawater, the salinity may be changed with the water variation. The evaporation of water caused by time or temperature leads to the salinity increasing. The salinity decreasing may be caused by the rainwater or running water accidentally. Thus, it is interesting to study that the influence of the seawater salinity on the performance and life of selflubricating spherical plain bearings.

PTFE/Kevlar fabric composites are commonly used as the self-lubricating materials in self-lubricating spherical plain bearings[4,5]. And it is the key material for selflubricating spherical plain bearings realizing selflubricating. The dry friction properties of PTFE/Kevlar fabric composites have been widely studied by the researchers. Tribological tests were carried out to evaluate the effect of the dispersion of nano-TiO2 in the selflubricating liner on the friction and wear properties[6]. Zhang Huijuan et al has studied the tribological behavior of the hybrid PTFE/cotton fabric composites filled with microsize $\mathrm{Sb} 2 \mathrm{O} 3$ and melamine cyanurate (MCA), observing that hybrid fillers (consists of $\mathrm{Sb} 2 \mathrm{O} 3$ and MCA) had a wear reduction effect on the hybrid PTFE/cotton fabric composites at lower loads but increased the wear rate at higher loads[7]. Su Fenghua et al found that the tribological performance of hybrid glass/PTFE fabric composites improved by filling 4\% nano-TiO2[8-9]. Kang Kejia et al investigated the antiwear performance of PTFE fabric composites under $45 \%, 60 \%, 75 \%$ humidity, and found that PTFE fabric composites has the best antiwear performance under $60 \%$ humidity [10]. Bramham et al [11] studied the influence of fluid contamination on the wear of dry bearing liners, pointed out that fluids generally increase wear to an extent depending on the level of stress, the type of fluid and the structure and composition of the liner material.

However, hardly any literature is available on the salinity effect to the friction and wear properties of PTFE/Kevlar fabric under seawater. Thus, it is meaningful for the concentrating on the salinity on the dry friction properties of PTFE/Kevlar fabric. The friction and wear test of PTFE/Kevlar fabric composites were carried out on MMU-5G friction and wear testing machine under four kinds of salinities seawater and running water. The wear 
surface morphologies were observed by CLSM to understand the wear mechanisms.

\section{EXPERIMENTAL}

\section{A. Specimen preparation}

PTFE/Kevlar fabrics were produced by rapier loom with broken twill weave. As shown in Fig .1, the weft is PTFE and the warp is Kevlar, thickness $0.35 \mathrm{~mm}$. Both of the upper sample and the lower sample were made of 45 steel. The Kevlar/PTFE fabrics were dipped in acetone for $12 \mathrm{~h}$, cleaned in the acetone solution, boiled $20 \mathrm{~min}$ in distilled water, and then dried in the oven at $80^{\circ} \mathrm{C}$ for $1 \mathrm{~h}$. The lower specimen was polished with $400 \#$ and $800 \#$ water sandpaper, and the upper specimen was polished with 600\#, 1200\# and 2000\# water sandpaper, and then both of the lower and upper specimens were cleaned 15 min in alcohol by ultrasonic wave. The fabric selflubricating liner was bonded on the surface of the lower specimen with the adhesive and curied at $180{ }^{\circ} \mathrm{C}$ for $2 \mathrm{~h}$ under contact pressure $0.2 \mathrm{MPa}$. Four different salinity waters are formulated by running water and sea salt.

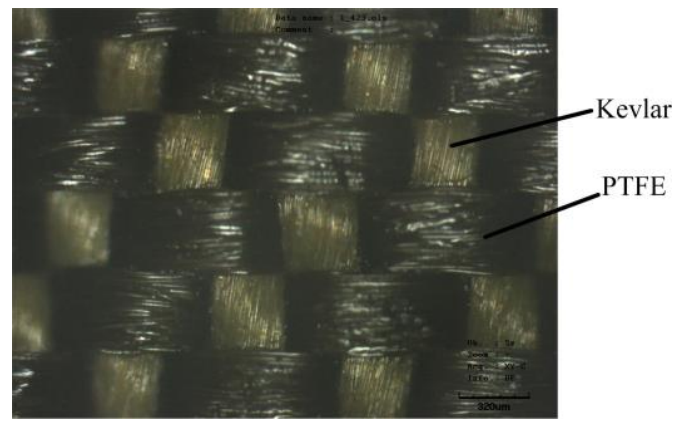

Figure 1. Photograph of PTFE/Kevlar Fabric $(\times 120)$

\section{B. Friction and wear test}

Tribological properties of PTFE/Kevlar fabric were studied under the laboratory condition by using ring-ondisc configuration (shown in Fig .2). The upper specimen continuous rotated around its own axis with the pre-set load $20 \mathrm{MPa}$ and slide velocity $0.2 \mathrm{~m} / \mathrm{s}$ in order to achieve sliding friction between the contact pairs. The wear depth could be measured by an improved fabric thickness meter (accuracy $0.01 \mathrm{~mm}$ ).

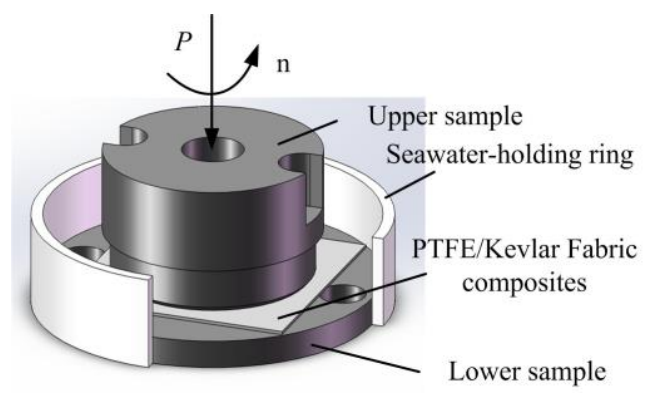

Figure 2. Schematic of ring-on-disc configuration
The specific wear rate was calculated using the following equation,

$$
\omega=\Delta V / P L
$$

Where, $\omega$ is specific wear rate in $\mathrm{m}^{3} / \mathrm{Nm}$, the volume loss in $\mathrm{m}^{3}, P$ the applied normal load in $\mathrm{N}, L$ the total sliding distance in $\mathrm{m}$

\section{RESULTS AND DISCUSSION}

Fig .3 shows the friction coefficient variation of PTFE/Kevlar fabric composites with different salinities of seawater under load $20 \mathrm{MPa}$ and slide velocity $0.2 \mathrm{~m} / \mathrm{s}$. As a comparison test, the running water is used in the test which the salinities is seen as $0 \%$. As seen from Fig .3 (a), the friction coefficient-time curves slowly decreases at the beginning, after the run-in process, the friction coefficienttime are almost stable in a certain value with some fluctuations under different salinities of seawater. The steady-state friction coefficient decreases with the increasing of salinities in range of $0 \% \sim 5 \%$, as shown in Fig .3 (b). While the steady-state friction coefficient of PTFE/Kevlar fabric composites in the salinities 5\% and $10 \%$ seawater are almost the same. Fig .4 shows the wear rate variation of PTFE/Kevlar fabric composites with different salinities of seawater under load $20 \mathrm{MPa}$ and slide velocity $0.2 \mathrm{~m} / \mathrm{s}$. It is seen that the wear rate increases with the salinities.

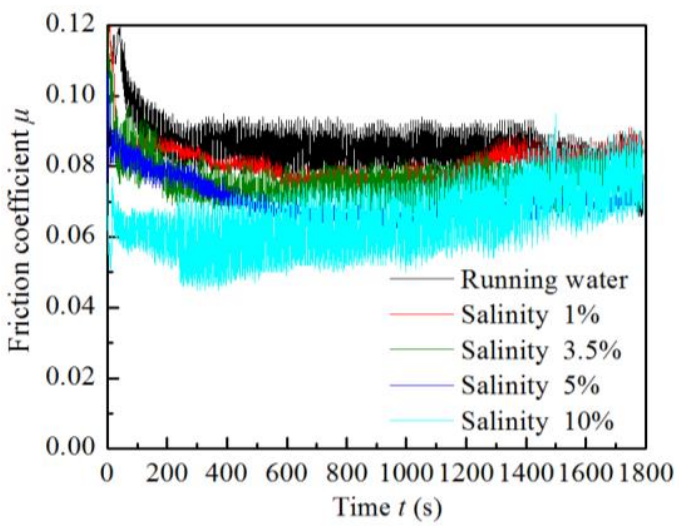

(a) Friction coefficients changing with time

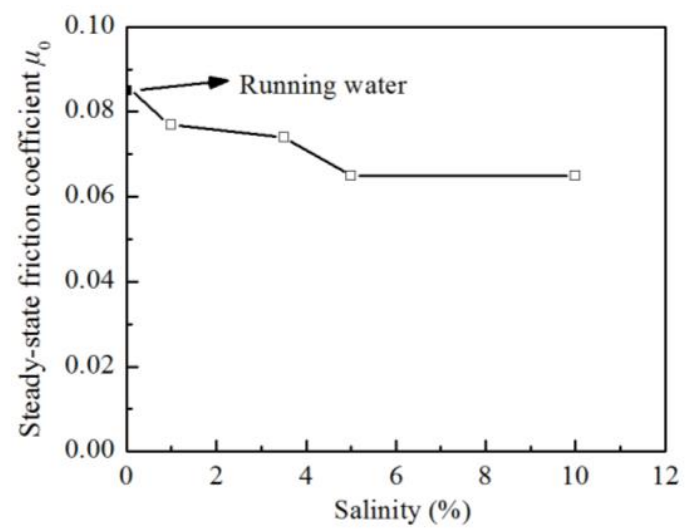

(b) Friction coefficients changing with salinity

Figure 3. Relationship of friction coefficient and salinity 


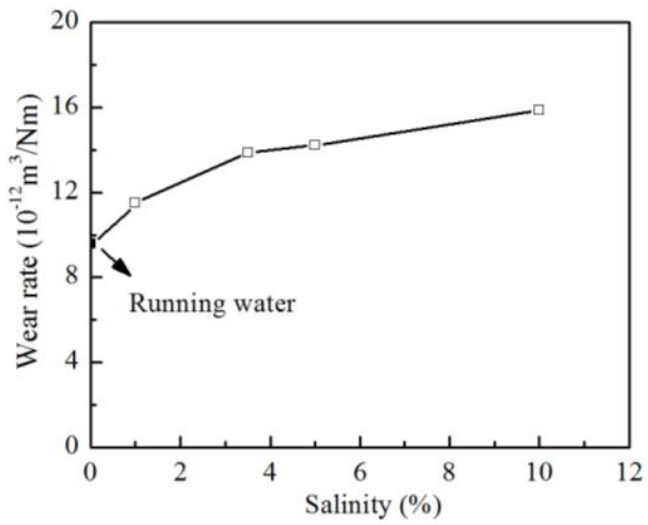

Figure 4. Wear rates changing with salinities

Fig .5 shows CLSM micrographs of the worn surface of PTFE/Kevlar fabric composites with different salinities of seawater and running water under load $20 \mathrm{MPa}$ and slide velocity $0.2 \mathrm{~m} / \mathrm{s}$. Fig .1 shows the unwear surface of PTFE/Kevlar fabric composites. The warp yarn is Kevlar fiber and the weft yarn is PTFE fiber. From Fig .1, it can be seen that the surface of PTFE/Kevlar fabric composites is uneven. This is mainly caused by the textile structure for the interweaving of PTFE and Kevlar fibers. So there are many "concaves" and "convexes" on the PTFE/Kevlar fabric composites. Fig .5(a) shows CLSM micrographs of PTFE/Kevlar fabric composites the worn surface under running water. It is seen that the worn surface of fabric composites in running water is smoother than the unwear surface for that the "convex" of PTFE and Kevlar has be wear out. A clear distinction of Kevlar and PTFE "convexes" which are worn out is still able to find, as shown the marked in Fig .5(a). Also, there are some "concaves" still be able to find. Some minor grooves being found in the worn surface shows that abrasive wear has happened. When compared the salinity of seawater, CLSM micrographs show the effect of increased salinity on the worn surfaces topography in terms of enhanced fiber damage, which was the major cause for increase in wear rate. In Fig .5(b), it is seen that most of these "concaves" are filled with wear debris. When Fig .5(c), (d) and (e) are compared, $10 \%$ salinity led to the excessive damage on both Kevlar and PTFE fiber, while 5\% salinity is mainly damage on PTFE fiber. It may be that the increasing salinities seawater leads to debond of the interface of PTFE and Kevlar fiber and adhesive. Thus the wear extent of PTFE/Kevlar fabric composites under salinity $5 \%$ is more serious than under salinity $3.5 \%$. But the increasing salinities caused the decreasing of friction coefficients by mechano-electrochemical interactions. On the other hand, corrosion may be happened on the surface of the steel upper sample, having a suppression effect on the generating of PTFE transfer film. Corrosion particles caused the grooves on the worn surface, seen as Fig .5. It can be seen from Fig .3(b) that friction coefficients of PTFE/Kevlar fabric composite decreased with the increasing salinities. The friction coefficient under salinity $6 \% \sim 10 \%$ is lower than others, however, the wear rates under salinity $6 \% \sim 10 \%$ is higher than others. By comparison, the friction coefficient is large when salinity $<3.5 \%$, while the wear rate is large when salinity $>5 \%$. So PTFE/Kevlar fabric composites used in seawater salinity
$3.5 \% \sim 5 \%$ have a relatively better antifriction and antiwear performance.

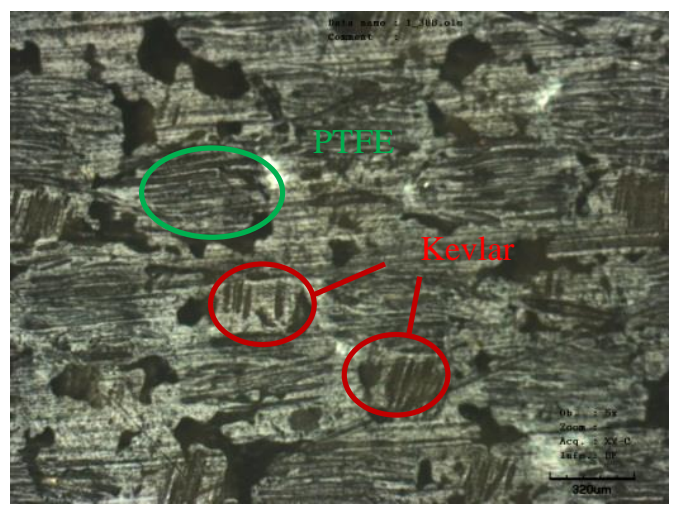

(a) Running water

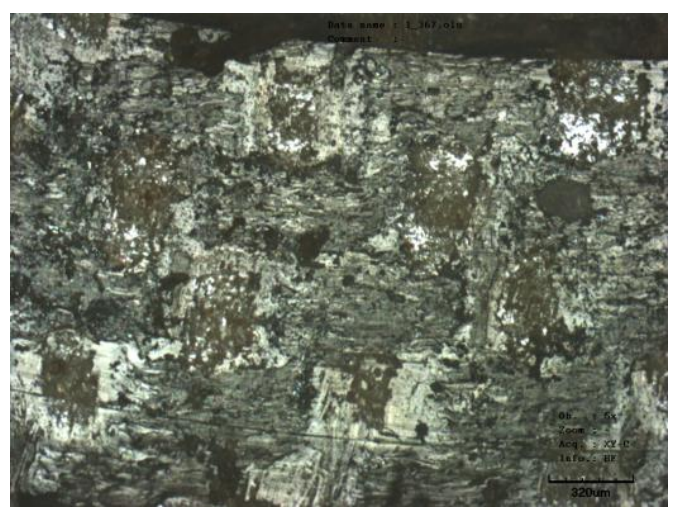

(b) Salinity $1 \%$

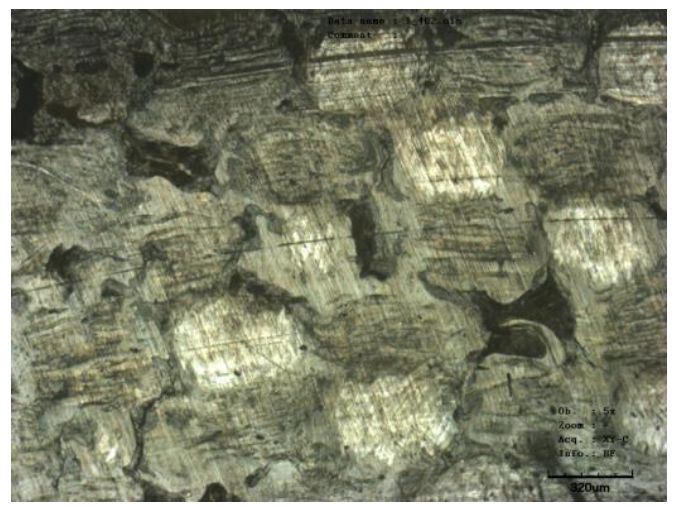

(c) Salinity $3.5 \%$

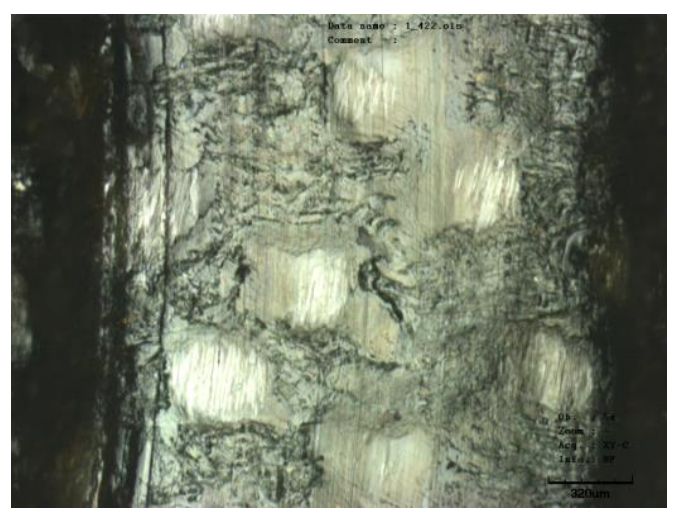

(d) Salinity $5 \%$ 


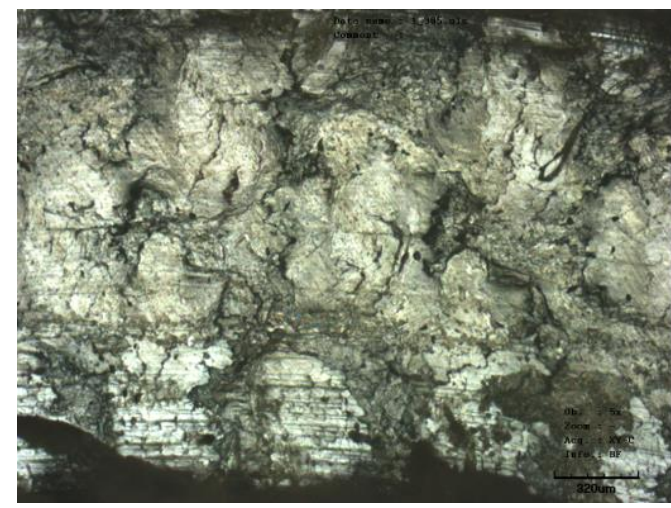

(e) Salinity $10 \%$

Figure 5. Worn surface of PTFE/Kevlar fabric composites under different salinities

\section{CONCLUSIONS}

In this study, we investigated the friction and wear performance of PTFE/Kevlar fabric composites under different salinities seawater. It is found that the steadystate friction coefficient of PTFE/Kevlar fabric composites decrease with the increasing of salinities. The wear rates increase with the increasing of salinities. The suitable salinities range for PTFE/Kevlar fabric composites is $3 \%$ $\sim 5 \%$. The friction coefficient is large when salinity $<3.5 \%$, while the wear rate is large when salinity $>5 \%$. The salinities have a corrosion and suppression effect on the upper steel sample. Thus, the mechano-electrochemical interactions and abrasive wear play an important role in the wear of PTFE/Kevlar fabric composites.

\section{ACKNOWLEDGMENT}

This work was supported by Natural Science Foundation of China (51405422), National Science and Technology Support Project (2014BAF08B03), Science and Technology Support Project of Qinhuangdao (201401A005), Young Teacher Autonomy Subject of
Yanshan University (13LGB001), Doctoral Fund of Yanshan University (B800).

\section{REFERENCES}

[1] Y. L. Yang, S. J. Huang, D. L. Zu, R. J. Zhang, X. W. QI, "Sliding wear of the hybrid Kevlar/PTFE fabric reinforced phenolic composite filled with Nano-titania," Chinese Journal of Mechanical Engineering, 2011, 24(1): 154-159.

[2] Z. Z. Zhang, F. H. Su, K. Wang, W. Jiang, X. H. Men, and W. M. Liu, "Study on the friction and wear properties of carbon fabric composites reinforced with micro- and nano- particles," Materials Science and Engineering A, 2005, 404(1-2): 251-258

[3] D. H. Xiang, W. C. Shu, and K. Li, "Friction and wear behavior of a new 40Cr steel-PTFE fabric composite under heavy loads," Materials Science and Engineering A, 2008, 483-484: 365-368.

[4] P. Liu, R. G. Lu, T. Huang, H. Y. Wang and T. S. Li, "A Study on the Mechanical and Tribological Properties of Carbon Fabric/PTFE Composites,"2012, 51(4): 786-797.

[5] X. W. Qi, Z. N. Jia, L. Lu, Y. L. Yang, and H. R. Liu, Tribological Behaviors of Hybrid PTFE/Kevlar Fabric Composite with Fine Serpentine Particle Under Dry Sliding Condition, Advanced Science Letters, 2012,6(1): 121-126.

[6] X. W. Qi, Z. N. Jia, and Y. L. Yang, "Influence of the Dispersion of Nano Titanium Dioxide on the Tribological Performance of Fabric Self-Lubricating Liner," Journal of Applied Polymer Science, 2013, 130(3): 2100-2105.

[7] H. J. Zhang, Z. Z. Zhang, F. Guo, W. Jiang, X. H. Men, and W. M. Liu, "Study on the tribological behavior of hybrid PTFE/cotton fabric composites filled with $\mathrm{Sb} 2 \mathrm{O} 3$ and melamine cyanurate," Tribology International, 2009, 42(7): 1061-1066.

[8] F. H. Su, Z. Z. Zhang, and W. M. Liu, "Tribological behavior of hybrid glass/PTFE fabric composites with phenolic resin binder and nano-TiO2 filler," Wear, 264(7-8): 562-570.

[9] F. H. Su, Z. Z. Zhang, W Jiang, K. Wang, and F. Guo, "Study on Tribological Properties of Nomex Fabr ic Composite Treated with Hydrolyzation/Grafting,” Tribology, 2006, 26(6): 551-555. (in chinese)

[10] K. J. Kang, S. M. Du, Y. Z. Zhang, and X. J. Pang, "Study on Dry Friction Behaviors of PTFE Braided Composites under High-speed Condition," Lubrication Engineering, 2012, 37(1): 10-12, 28.

[11] R. W. Bramham, R. B. King, and J. K. Lancaster, "The wear of PTFE-containing dry bearing liners contaminated by fluids," ASLE Transactions, 1981, 24(4): 479-489. 